\title{
Elwood Murray's Interdisciplinary Analogue Laboratory
}

Judith Brownell

State University of New York, Cortland

Elwood Murray joined the faculty of the Department of Dramatic Arts and Speech at the University of Denver in 1931 and within a year had assumed the responsibilities of chairman.[1] The history of the department for the next thirty years was molded by the philosophy and aspirations of this man, who believes that speech is a broad and interdisciplinary subject and that speech training is essential for every individual.

As chairman, one of Murray's first priorities was the development of curriculum. Courses in speech and personality adjustment, business and professional speaking, discussion, and speech science were introduced.[2] By 1940, Denver had established a thriving speech clinic which served not only the speech handicapped, but supplemented work in the department's basic speech course as well.[3] In the summer of 1932, Murray organized the first annual Rocky Mountain Speech Conference which was credited as "the most representative speech gathering" ever held in the Rocky Mountain Region.[4] Four years later, Murray initiated a summer institute at the 
University of Denver for high school students.[5] These summer programs drew well-known scholars who came from throughout the country to participate and share the latest developments in the speech field.[6]

In addition to expanding Denver's curriculum, Murray also gained scholarly recognition through his early writing and research in the area of speech and personality.[7] Influenced by the background in holistic and organismal psychology he had received as a graduate student at the University of lowa, Murray developed many of these ideas in his own work.[8] In 1937, the year he became president of the Western Association of Teachers of Speech, Murray's first and perhaps best known text was published. The Speech Personality presented a "mental hygiene" approach and suggested that the ultimate goal of speech training is the development of a mature, integrated personality.[9] Personal integration and adjustment are seen as prerequisites to effective speech behavior.[10]

The theme of integration continued to characterize much of Murray's work in the years to come. His training with Alfred Korzybski at the Institute of General Semantics in the early 1940's further strengthened his holistic, relational orientation.[11] In 1953, Murray coauthored a second text, Integrative Speech, which focused on the individual's ability to bring about "social integration" within groups,[12] thereby facilitating a "search for the facts" and fostering warm, cooperative relationships among people.[13] The principles of general semantics came to be seen as a means for acquiring the necessary attitudes and forming habits of perception which encourage a fact-oriented, relational point of view.[14] Throughout the following years, 
Murray encouraged the acceptance and application of general semantics within the speech field.[15]

In addition to his study with Korzybski, Murray's early work was influenced by Jacob L. Moreno and Kurt Lewin.[16] Sociodrama, sociometry, and group dynamics techniques became important "methodologies" in Murray's classes.[17] Perhaps his most noteworthy application of these methods was in his Laboratory in Interpersonal Communication (1949), designed to teach students the principles of general semantics.[18] This laboratory, along with offerings such as Origins and Sources of General Semantics, Intercultural Communication, Industrial Communication, Sociodrama for Speech Situations, and Communication in Human Organizations,[19] became the basis for Denver's pioneering program in Communication Methodology.[20] A statement by the Department of Speech in 1964, following Murray's retirement as chairman, read: “The major strength of the speech department at the University of Denver has been in the area of communication methodology and general semantics. ... Due to the pioneering work of Elwood Murray we have established a national reputation in the area of . . . communication methods ... there is increased recognition across the country that the University of Denver's speech department has established itself as the strongest school in the nation in this new frontier of communication."[21]

Exposure to the concepts of cybernetics and what was to become known as general systems theory in the early 1950's encouraged Murray to broaden his scope still further. He saw the principles of integration at work not only within the individual 
and his social groups, but also in all multilevel systems and subsystems throughout the universe.[22] Through the perception of relationships, Murray believes, individuals can reach the understanding and harmony which enable them to act effectively within society. Murray's third text, Speech: Science-Art (1969), reflected the general systems point of view and presented a relational model of communication.[23] "Things may appear separated," the authors of Speech: Science-Art stated, "but only to the nonperceptive man."[24] As Charlotte Read commented, Murray himself was a "pioneer in seeing relationships."[25]

Murray continually encouraged others to adopt this relational orientation, maintaining that as society becomes increasingly complex, individuals isolate themselves into separate spheres of work and understanding; due to increasing specialization, various members of society-managers, educators, farmers, engineers, artists - are unable to communicate with one another.[26] Individuals therefore act with little or no knowledge of the consequences of their behavior. The average person, it would seem, has difficulty making decisions, predicting outcomes, deciding what is important.

Much of the blame for this lack of communication between members of society rested, Murray held, in the structure and goals of our educational institutions.[27] As technological advance demanded increased specialization, education complied. Absorbed in narrow channels of study, students' vision is often limited, preventing any clear or unified concept of what the outside world is really like. This fragmentation further prevents students from perceiving their courses-and later the subjects with 
which they are concerned-in any kind of meaningful relationship either with one another or to themselves.

Encouraging greater interdisciplinary communication became, for Murray, one of the most important challenges of his teaching career.[28] He hoped to contribute to this goal by designing a group experience that could be used by speech teachers in any university. His plan, which was the culmination of years of work in this direction, applied his earlier communication methodologies to facilitate the building of analogues and encouraged scholars to see relationships between their fields of knowledge. Murray called this innovative approach to an age-old concept the Interdisciplinary Analogue Laboratory.

\section{THE ANALOGUE PROCESS}

From his extensive work and background in general semantics and general systems theory, Murray had become interested in trying to identify some of the yet undiscovered "basic structures" of the universe.[29] A clear understanding of what is meant by "structure" is important in grasping the objectives and operations of the analogue laboratory. Every object or event in the environment can be seen to exhibit structure, which Alfred Korzybski characterized as a "complex of ordered and interrelated parts." Murray explained, "Whatever the situation, deep and sufficiently long continued research gradually reveals the structure of relations which are repeated time and time again with infinitely many variations. When structure is ascertained, predictability improves and wiser action becomes possible."[30] 
To perceive these basic structures, one must observe the specific, concrete facts as they occur in our environment. Focusing on structure, then, forces an orientation away from language and onto the "realities" of the world that surrounds us. Basic structures can be identified in all orders of knowledge and on all levels of complexity.[31] As the authors of Speech: Science-Art explained, some structures "range into the submicroscopic, some range into and beyond the galaxies."[32] Several of the most easily identified structures can be found in physics, where gravitation, induction, electricity, and so forth serve as the "basic structures" of this discipline. The question then arises, how does identifying these patterns help us to interrelate our knowledge from diverse disciplines? How do these basic structures function to help us better understand our world?

One specific method by which relationships between knowledge might be discovered is through the building of analogues. If a basic structure is identified within one discipline, it can then serve as a model on which an "analogue" of that structure as it appears in some other field may be built. The perception of relationships -in this case structural similarities - between different events occurring within various disciplines is thus facilitated. As Leonard C. Hawes explains, when building an analogue, the substance of a particular event is "stripped away," leaving a structure on which a new substance is then mapped.[33]

Many scholars have recognized the potential of the analogue approach. One recent example is the application of principles from epidemiology to explain the process of information diffusion by the mass media: "Consider, for example, the state 
of scientists' ability to explain the 'spread' of new information and innovations in a community or culture. ... At some point, the better developed theories of epidemiology, which explained the 'spread' of diseases, were used as analogues; some similarity in the dynamics of the two 'spread' phenomena was suspected.'[34]

An analogue model, then, allows a familiar structure or concept to be used as a basis for understanding more thoroughly or discovering new insights about a less understood structure. The most exciting and provocative analogues are often those that come from dissimilar disciplines, as they lead to an exploration of ideas not previously considered. One of the greatest values of the analogue is for the "discovery" phase of inquiry. Known information about the model structure is used to predict possible similarities in the analogous structure which may then be tested empirically. The building of analogues, therefore, becomes a creative as well as a scientific process. As Leonard Hawes aptly states, "The common element of 'original' science and art ... is the creative intellectual act."[35]

\section{OPERATIONS OF THE INTERDISCIPLINARY ANALOGUE LABORATORY}

Recognizing the potential benefits to be gained through the analogue method, Murray gradually evolved a plan for the practical application of the analogue approach within the speech curriculum at the University of Denver: "The ability to make comparisons and to establish correspondences seems to be the most basic behavior for predicting, inferring, and adjusting. But to see across departmental boundary lines one must carry comparing to a different order, to the level of analogy. Analogical 
thinking enables persons to relate entities horizontally; it makes possible the connecting of dynamic structures."[36]

During the summer and fall of 1956, students in an advanced seminar in communication theory and Murray's Laboratory in Interpersonal Communication experimented with the idea of building cross-disciplinary analogues which might promote the integration of knowledge. These "units," built upon basic structures from physics, were generated from figurative analogies which related the structures of one discipline to those of another.[37] Murray vividly recalled: "There was considerable thrill and enthusiasm as it became apparent to them that 'polarization,' at least in principle, was observable in all departments and specialities which they had time to investigate. The same was true of the other solid fact structures which were represented by gravitation, radiation, energy, resonance, entropy, feedback."[38] From this experimental work, it became apparent that analogue units had potential for unifying knowledge and increasing students' awareness of the relationships between structures from different disciplines. The search for analogues also brought out, Murray believed, more creativity than other academic activities as it forced students to deepen their knowledge of the subject matter concerned.

The first Interdisciplinary Analogue Laboratory was not initiated until the summer of 1965. As Murray explained, "I had the idea for the laboratory about five or ten years before I tried it. I didn't have nerve enough to put it down as a course. ... I was scared to take it through a committee of specialists, you know. Boy, that's the last thing that they would accept!'’39] 
The specific plan for the laboratory evolved when Murray was a visiting professor at Southern Illinois University in 1963. With the help of Dr. E. Claude Coleman, then head of the Honors Program at Southern Illinois, the basic foundation of the laboratory was established.[40] The next summer, curriculum heads from both the Universities of Denver and Southern Illinois met to finalize plans for the interdisciplinary offering.[41] The goals of the laboratory, as presented in one early brochure, were to:

1. provide experience in deep level communication among scholars and educators from all basic areas of the curriculum.

2. ascertain the relational structures, patterns, and themes fundamental to more than one discipline.

3. arrange, in the area group sessions, the scientific structures in a priority of importance for human survival and development.

4. build analogue units which members of the laboratory might use to illustrate and illuminate their specific teaching areas.

5. promote the critical and creative potential of students.

6. work toward the development of an all-inclusive Communication Theory.[42]

Ideally, the laboratory met weekly throughout the entire school year, each session requiring approximately four hours. The major work of the laboratory was carried out through two different sets of groups, each with different functions.[43] The first group was homogeneous, comprised of members from each of the various departments 
within the university - the natural sciences, social sciences, humanities, administration, etc. The function of this group was to agree upon the basic or fundamental structures within their discipline, or formulate specific problems within the discipline which they would like to explore. Typically, Murray might begin by asking the group something like, "What are the basic structures within your discipline that you would like to illuminate?" The members then strove to uncover basic patterns or themes. One of the earliest analogue offerings was entitled "A Search for Common Structure," where students initiated such analogue units as "Energy Transformation," "Interaction Patterns," and "Time-Binding." Other laboratories were problem solving in nature and used analogues from other disciplines to shed light on a particular problem by suggesting possible solutions.[44]

The second analogue group was as diverse as possible. Within this group, the goal was to develop analogues to the structures presented by members of each of the different disciplines represented. Murray describes the process that took place: "Each member would have to explain it ... you ask this fellow on the right, "What does that remind you of?' Then you'd go to the next one in social sciences and ask, 'What does it remind you of?' Put it all down in your notebook ... you got a lot of material there, analogues. ..."[45] Depending upon the particular theme of the laboratory - whether to illuminate specific problems within each discipline, create integrated units for classroom use, or simply discover structures common to several disciplines - the process was generally the same. 
Criteria for testing the validity of each analogue produced were also evolved within the laboratory. Many of the ideas generated within the groups were discarded as students discovered that, if extended far enough, analogies could be perceived in any two structures regardless of how dissimilar. Students were, however, still able to derive enough material to write a paper based on the theme they had chosen to develop.[46] The group processes within the laboratory brought the sciences and arts into greater communication with one another. The number of analogies - from poetry, music, history, chemistry - were limited only by the backgrounds of the group members present. The two groups alternated in their meetings as necessary in order to complete analogues for all participants. Members also rotated among groups which permitted every scholar to interact with as many other members of the laboratory as possible. As one former student commented, "I have never been able to understand Dr. Murray's genius in getting people from so many different fields to work together. ... He brought people from all levels of business, industry, education, etc. together and involved them in the communication process." [47]

Special guests were frequently brought in to serve as resource persons and observe the laboratory process. In addition, members of the class were selected to serve in a variety of roles, among them research director, clerical assistant, and editor for the completed manuscripts. Students also alternated as observers, critics, and evaluators of the laboratory operations.[48] As was the case in all of Murray's laboratories, students gradually took over more and more of their own management as the semester progressed. Although some students found the laboratory difficult to 
understand and were at first reluctant to participate in group activities, the initial resistance was usually overcome. Murray recalls: "Right from the beginning, I got some opposition and I scared two or three of them out ... those that didn't have it on the ball. Well, after about the third day they all got into the excitement. There was real excitement from then on. The excitement was so great sometimes in the small groups I could not interfere. I didn't want to come in, I would break the magic. Oh, that magic integration that was going on! The activity!"[49]

In addition to the alternating group activities, which comprised the basic format of the laboratory, lectures were given at each meeting on some aspect of integrative methodology. As Murray described the three major areas covered in one of his earliest laboratories, the units included general semantics, group dynamics, and problems in communication.[50]

In general semantics, students first had to gain a thorough understanding of the formulations such as nonallness, nonidentification, abstracting, extensionality, isomorphism, etc.[51] This knowledge of language and the symbolizing process was essential for the laboratory to function effectively, since participants were required to analyze their own language behaviors.[52] Understanding and internalizing general semantics' principles would automatically help students adopt the appropriate perspective for effective participation within the laboratory setting. Murray wrote in 1959: "General semantics brings a methodology for searching into, for evaluating, and for coping with the relationships and interactions among the various orders of factphenomena from the smallest to those from which we are able to abstract information 
with the aid of extra neural extensions to our senses, to those from which we are able to abstract information within the limitations of our senses .... there is a constant emphasis upon human beings within all of the orders of their relationships."[53] Laboratory groups, effectively employing group dynamics, socio-drama, and role-playing techniques, were periodically required to summarize and present their work before the class. In order to conduct a successful laboratory, then, the instructor needed not only the widest possible background, but also a knowledge of general semantics and the methodologies to teach it.[54] By its very nature, the laboratory process operated on several levels simultaneously. The nondirective methods of the instructor were designed to maximize initiative and creativity on the part of class members. As one former student explained: "He offers a few introductory remarks, usually on a high level of abstraction, then leaves it up to you to figure out what he's talking about. As I see it, this starts with chaos and leads to forcing you to think for yourself. He merely slips his apparently vague notions to you very quietly, almost as if he is not sure of what he's saying, evoking questions, arguments, etc. Some people underestimate him, which proves a grave error."[55] While students were learning "content," they were also practicing how to work together as a group and communicate more effectively with scholars from other disciplines. As Paul Hunsinger commented concerning the laboratory experience of 1970: "There is an obvious level of learning that takes place in a conscious manner, and there is a much deeper level of learning that takes place unconsciously. A teacher often teaches more than he realizes by his life example, and this class has learned more from Dr. Murray this quarter than 
he will ever realize. He has shared with us his knowledge and enthusiasm and we share with him our love, understanding, and deep respect."[56]

\section{CONCLUSION}

Through the operations and content of the Interdisciplinary Analogue

Laboratory, then, Murray anticipated that students would accomplish several important objectives. First, communication among the specializations would result as mental and verbal barriers were broken. Through participation in the laboratory process, students would begin to see the interrelatedness of all knowledge and realize the necessity for expanding their understanding of the world beyond the narrow range of one discipline. Also, more effective communication would be facilitated by a greater awareness of the symbolizing process itself. As Murray stated, he hoped that the laboratory experience would enable the individual "virtually to transcend himself ... to see things whole, the better to blossom into his full competency and creativity."[57] Such individuals would have the necessary background to assume positions of leadership in business, industry, and education alike.

The process of constructing analogues also develops both critical and creative capacities, which results in fresh viewpoints for perceiving and studying each discipline. As Leonard Hawes stated, "there is no statistic or design . . . that can replace human imagination and insight. But statistics and designs can be used imaginatively to ask previously unaskable questions."[58] It was this creative impulse that the analogue laboratory strove to capture and encourage. Scholars interested in 
developing new modes and directions in research as well as educators looking for new ways to facilitate student learning could derive benefit from the analogue laboratory. Although the analogue laboratory was designed to fulfill the needs of scholars from all fields, the value of the laboratory for teachers is perhaps most apparent. After having learned the analogue approach to integrating knowledge, teachers would be in a better position to illustrate the relationships between the content of various disciplines in the teaching of their particular subject matter. They would further be prepared to organize their courses around the relational structures that were found to be fundamental to more than one discipline, instead of viewing the content of their own area in isolation from the broader curriculum of which it was a part.

From Murray's perspective, however, the overriding goal of his laboratory was eventually to permit the unification of all knowledge. Although through the process of building analogues similar structures within several disciplines could be identified, it has been a challenge of human knowledge to discover the several all-pervasive, recurring structures of the universe which unite all knowledges. Murray saw the analogue laboratory as a possible means to this end. By continuing, year after year, to formulate analogues between the basic structures of different disciplines, recurring patterns would hopefully emerge. Murray envisioned, eventually, a volume entitled "Basic Structures of the Universe" which would be a culmination of the work of several Interdisciplinary Analogue Laboratories. This anthology would be an invaluable resource, Murray believed, to the development of general education, providing the 
basis upon which knowledge from different disciplines could be related and around which the entire college curriculum could be restructured.

Murray envisioned, then, the Interdisciplinary Analogue Laboratory having a prominent place in the speech curriculum and being offered to graduate students and faculty on college campuses throughout the country. Reaching even a handful of interested instructors would potentially affect the education of thousands of students who would be taught to view themselves and the world around them as a dynamic, integrated whole.[59]

To date, however, few Interdisciplinary Analogue Laboratories have been taught outside of the University of Denver or by anyone except Elwood Murray.[60] Although many students may have rearranged their courses and reorganized their curricular priorities as a result of their laboratory experience, it is difficult to identify many who have gone on to replicate Murray's laboratory.[61] Recently, Murray himself has been encouraging retired Denver faculty to form an Analogue Society which would continue the work begun in his seminars. Such a society, Murray hopes, would eventually expand and form chapters in communities across the country.[62] Still, Murray's dream of the time when Analogue Laboratories would be offered on a full scale to faculties of colleges and universities has not yet arrived.

One reason why Murray's laboratory has not been duplicated at other universities may be because the conditions, the environment, are not appropriate to foster such an approach. As Alvin Goldberg noted, you cannot take a faculty member and put "Interdisciplinary Analogue Laboratory" on his teaching schedule as you could 
Public Speaking or Discussion or Oral Interpretation.[63] Such an offering demands someone with a very special background and with very special sensitivities to the purpose and goals for which the laboratory was designed. Such an offering, too, must "fit" with the rest of the curriculum and must be in keeping with the philosophy and aspirations of the particular department and university.

Most likely, however, the major reason the laboratory has not been carried on is that relatively few speech scholars have been sympathetic to or trained in the general semantics approach on which the laboratory is based. The general semanticist has been looked upon by more traditional speech educators as "esoteric," advocating principles and methods that many feel lack academic respectability. As John Newman aptly stated only a few years before the first Interdisciplinary Analogue Laboratory: "There are few things that seem to be more fun than taking pot shots at general semantics. It is a time honored sport, and after some twenty five or thirty years of it, the veteran observer has probably long since been witness to every possible variety thereof."[64]

Murray himself encountered criticism of his methods from both within and outside of his department. As he explained his situation at the University of Denver: "I got criticism from upstairs ... I suppose some administrators didn't understand general semantics, what I was doing was strange to them. New deans would come in and it would take them three years to understand what we were trying to do in speech. Oh, that was a frustrating thing I had to live with."[65] Criticism, however, seldom daunted Murray's enthusiasm for an approach he felt was sound. He has frequently been called 
a "pioneer," a "maverick,"[66] pursuing the "scientific basis" of speech which many thought to be highly disrespectable. He continued to experiment with nontraditional ideas even in the face of strong opposition, hoping to contribute to our understanding of effective speech.[67]

In our present age, when society is faced with the problems of increasing specialization, of barriers to communication imposed by narrow perspectives, and of lack of understanding between individuals in different spheres of concern, the need for establishing a means of working toward common ground and cooperation seems more crucial than ever. As Murray often reminded us, the college curriculum has played a major role in perpetuating, if not developing, many problems of communication. It would not seem unreasonable, then, to wonder if the Interdisciplinary Analogue Laboratory could have value today for promoting the general education of students. If so, our most important resource is right at hand-those scholars from all fields who are concerned about the future and challenged by the task of interdisciplinary unification. Through experimentation with analogue approaches to the integration of knowledge, such as Elwood Murray's pioneering laboratory, we have nothing to lose and much to gain. 


\section{NOTES}

[1] When Elwood Murray replaced Walter Sinclair as chairman of the Department of Dramatic Arts and Speech in 1932, the department was retitled the Department of Speech and Dramatic Arts. In 1943, much to Murray's dismay, speech and theatre split and became separate schools within the university. Upon Murray's retirement as director, the School of Speech became the Department of Speech. In 1966, Murray received Emeritus Professorship from the University of Denver, and three years later his fellow colleagues presented him with a festchrift, Language Behavior, on the occasion of his retirement from full-time teaching.

[2] "Speech Pathology," first offered in the spring semester of 1932, is believed to have been the first speech science course west of the Missouri River (Interview with Elwood Murray, University of Denver, June 26, 1977; University of Denver College Catalogue, 1931-1932, p. 81).

[3] A concentration in Speech Pathology and Correction was added to the department in 1933. During the early years of the speech clinic, Dr. C. S. Bluemel was very influential in strengthening the clinic program. In 1940, Edna Hill Young, known for her work in the moto- kinesthetic method of speech correction, joined the staff.

[4] "Speech Conference: First Annual Rocky Mountain Speech Conference, Where Speech Was Golden," University of Denver Bulletin 33 (January, 1932), 1. The Rocky Mountain Speech Conference, which continued at the University of Denver for over thirty years, provided an opportunity for speech educators from throughout the west to share their thoughts on speech training. Each conference adopted a particular "theme," which was developed around what Murray felt to be a vital issue of the time.

[5] Juniors in high school were recommended by their speech teachers for four weeks of special training in debate, drama, or radio. Approximately sixty students attended during each half of the summer. By 1944, twenty scholarships were being given to students in each of the three areas in an effort to "encourage worthy talent in the speech arts, encourage the promotion of adequate speech programs in the high schools of the country, and to foster the adoption of improved methods of speech education" (Summer school brochure, University of Denver, 1944-1945).

[6] Murray was seldom reluctant to call upon experts in any field who might be able and willing to contribute to his summer programs. Among the participants were Ralph 
Nichols, Jacob L. Moreno, Alfred Korzybski, S. I. Hayakawa, and Lee Edward Travis (Summer school brochures, University of Denver Penrose Library).

[7] The research conducted by students in Denver's growing graduate program helped establish Denver-along with the Universities of lowa and Minnesota-as a pioneer in studies relating personality to speech behavior. Franklin Knower noted the first theses written at the University of Denver which reflected this speech- personality orientation (Franklin Knower, "Index to Graduate Work in Speech," Speech Monographs, 2 (September, 1935), 8). A summary of this early work was published by Murray (1944) and recognized as one of the first such summary studies to appear in speech literature (Wayne N. Thompson, Quantitative Research in Public Address and Communication (New York: Random House, 1967), pp. 18, 25, 188).

[8] Murray received his master's degree from the University of lowa in 1924 and his doctorate in 1931. His studies with such scholars as Charles Henry Woolbert, A. Craig Baird, Wolfgang Koehler, and Lee Edward Travis had a lasting influence on his work. A course with Raymond Wheeler (The Science of Psychology (New York: Thomas Y. Crowell and Company, 1929)) provided valuable insight into what was called organismic or "holistic" psychology.

[9] Elwood Murray, The Speech Personality (New York: J. B. Lippincott, 1937). The Speech Personality was revised in 1942 to include an additional chapter on general semantics.

[10] Murray's articles on personal integration include "Speech Training as a Mental Hygiene Method," The Quarterly Journal of Speech, 20 (February, 1934), 37-47, and "A Study of Factors Contributing to the Maladjustment of the Speech Personality," Speech Monographs, 3 (October, 1936), 95-108.

[11] Murray has been actively involved in general semantics activities since he participated in five of Korzybski's seminars beginning in 1939. On Murray's initiative, the University of Denver hosted the Second (1941) and Third (1949) International Conference on General Semantics. In 1944, Murray was appointed to the Board of Governors of the International Society for General Semantics, and in 1948 he became a member of the Board of Trustees of Korzybski's General Semantics Institute. Dr. Murray became director of the Institute in 1967 and continued in that capacity until 1969, when he was given the status of Emeritus Director. In 1975, Murray was made one of three advisors to the Board of Governors of the International Society for General 
Semantics, and in 1978 was honored with being chosen as the Korzybski Memorial Lecturer.

[12] Elwood Murray, Raymond Barnard, and J. V. Garland, Integrative Speech (New York: Dryden Press, 1953). See also Elwood Murray, "Speech as a Social Integrator," Proceedings of the Ninth Annual Convention of the Western Association of Teachers of Speech, Denver, Colorado, November 25-27, 1937; Elwood Murray, "Speech Standards and Social Integration," The Quarterly Journal of Speech, 26 (February, 1940), 73-80; Elwood Murray, "The Integrative Functions of Speech," The Teachers College Journal, 13, No. 2 (January, 1942), 57-65.

[13] Many of Murray's ideas concerning the nature of effective speech developed from his discussions with Dr. Fritz Kunkel, who introduced him to the premises of "We" psychology. Kunkel's theories emphasized the importance of warmth in social contacts, which was seen as an indicator of mental health. Murray first met Kunkel when he was lecturing at Estes Park during the summer of 1936 (See Fritz Kunkel, Let's Be Normal (New York: Ives Washburn, 1935); Fritz Kunkel, Conquer Yourself (New York: Ives Washburn, 1935)).

[14] Elwood Murray, "What Is It All About?" (Paper delivered at the Convention of the Speech Association of America, Boston, Massachusetts, August 28, 1957); Elwood Murray, "Corridors among the Ivory Towers: A Relational-Communication Approach to Unification of the College Curriculum," The Western Business Review (February, 1961), 44-60.

[15] In 1956, Murray initiated the Speech Association of America's interest group in General Semantics and Related Methodologies and became its first chairman. Murray felt that he was very influential in getting general semantics into the SAA: "Every paper I delivered during the 1940's, 1950's, and 1960's was related to general semantics. As long as I could keep the interest group growing we had a fine program every year" (Interview with Elwood Murray, June 28, 1977). Recently, Murray was elected a Fellow of the General Semantics Institute. This honor, Charlotte Read explained, is "reserved for a few workers who contributed significantly to general semantics" (Letter from Charlotte Read, New York, October 5, 1977).

[16] On several occasions, Jacob Moreno participated in the University of Denver's summer programs. Courses in sociodrama were part of the curriculum in Communication Methodology, and Moreno's techniques became an important aspect of Murray's laboratories. In the summer of 1949, Murray attended Lewin's National 
Laboratory on Group Development and returned to introduce into his own Laboratory in Interpersonal Communication many of the group dynamics principles he had encountered.

[17] Murray uses the term "methodology" in a very broad sense as it refers to any technique or approach which facilitates the learning process-even speech itself. It is almost impossible to find an article written after 1950 that does not include this term.

[18] Murray has been credited by many of his students and colleagues as having pioneered in the use of laboratory methods in speech. His Laboratory in Interpersonal Communication was an elaborate framework designed to assist students in internalizing the principles of general semantics. Two of Murray's former students, Gail Myers and Michele Tolela Myers, have written a text based largely on the Interpersonal Laboratory. The Dynamics of Communication: A Laboratory Approach (New York: McGraw- Hill, Inc., 1973, 1976) has proven successful (McGraw-Hill reported that over 11,000 copies have been sold), indicating that educators throughout the country have found Murray's laboratory approach to be a viable and effective teaching method.

[19] Many of the courses in the communication methodology program were among the first of their kind. Murray's offerings in Intercultural and Industrial Communication, first taught in 1948, were some of the earliest in those areas.

[20] As the editors of Language Behavior explained: "It was this expanded view of the responsibilities of the communication specialist that caused Elwood Murray to enlarge his communication study and research interests and to offer course work in many new areas. To identify the speech curriculum he pioneered in general semantics, group and organizational communication, linguistics, and language disorders, Murray used the phrase 'Communication Methodology' " ("Preface," Language Behavior (The Hague, Netherlands, 1969), p. 10). Also see Alvin Goldberg, "Communication Methodology," paper presented at the Communication Colloquium, University of Wisconsin, Milwaukee, October 16, 1967.

[21] "Assumption No. 31," Report of the Denver Retreat, 1964, p. 42.

[22] Elwood Murray, "Streamlining the Speech Edifice: I," Western Speech, 23 (Fall, 1959), 197202; Elwood Murray and Dan McLachlan, "Parallels of General Semantics and Cybernetics," Paper presented to the psychology section, Colorado-Wyoming Academy of Science, Greeley, Colorado, May 5, 1962; Elwood Murray, "How to Help Our Environments Help Us," Paper presented at a convocation of the student body at 
Hastings College, Hastings, Nebraska, October 6, 1964; Elwood Murray, "Communication and the Grand Analogue," Paper presented at the Convention of the Western Speech Association, Boulder, Colorado, April 2, 1965

[23] Elwood Murray, Gerald M. Phillips, and David J. Truby, Speech: Science-Art (New York: The Bobbs-Memll Company, Inc., 1969).

[24] Ibid., p. 207.

[25] Letter from Charlotte Read, New York, October 5, 1977 (Charlotte Read is presently director of the General Semantics Institute in New York. She worked many years with Korzybski before his death and has written numerous articles and papers in general semantics.).

[26] Murray's concern about the lack of communication between scholars from different fields was one factor which prompted him to take an active role in founding the National Society for the Study of Communication in 1949 (See Carl Weaver, History of the International Communication Association, unpublished manuscript commissioned by the International Communication Association, 1974). "This organization is structured," Murray stated as he assumed the presidency in 1952, ". . . not only to give ... speech approaches their natural place as the integrating core in the curriculum, but also to encourage disciplines in improving communication at all levels. . .. " (Elwood Murray, "The Gilman Plan for the Reorganization of the Speech Association of America: A Symposium," Paul D. Bagwell, ed., The Quarterly Journal of Speech, 38 (October, 1952), 334).

[27] Elwood Murray and James E. Perdue, "General Semantics in an Interdisciplinary Educational Program: Plan for a Laboratory in the Integration of Knowledge," Etc.: A Review of General Semantics, 14 (Autumn, 1956), 40.

[28] Murray was responsible for initiating several interdisciplinary research conferences, which he hoped would provide scholars from various fields with an opportunity to share their knowledge. The resulting volumes include: Communication'. General Semantic Perspectives, Lee Thayer, ed. (New York: Spartan Books, 1970); Research Designs in General Semantics, Kenneth Johnson, ed. (New York: Gordon and Breach, Science Publishers, 1974); Coping With Increasing Complexity, Donald Washburn and Dennis Smith, eds. (New York: Gordon and Breach, Science Publishers, 1974). 
[29] Murray's third text, Speech: Science-Art (1969), presents a thorough discussion of such concepts as "structure," "transformation," and "isomorphism," all important ideas in his later work.

[30] Elwood Murray and James E. Perdue, "General Semantics," 40.

[31] See Murray, Phillips, and Truby, Speech: Science-Art, pp. 205-07.

[32] Ibid., p. 206.

[33] Leonard C. Hawes, Pragmatics of Analogizing: Theory and Model Construction in Communication (Mass: Addison-Wesley Publishing Company, 1975), pp. 112-13.

[34] Ibid., p. 112.

[35] Ibid., p. 17.

[36] Murray and Perdue, "General Semantics," 41.

[37] Elwood Murray and Paul Hunsinger, "The Interdisciplinary Analogue Laboratory on Structures, Patterns, and Themes," unpublished paper, 1968; also see Elwood Murray, "Future Directions in Communication Research: An Assessment of the Possible Use of Analogues," The Journal of Communication, 11 (March, 1961), 3-12, 33.

[38] Elwood Murray and James E. Perdue, "From the Atom to Beethoven to You: General Semantics in the College Curriculum for a Space Age," offprinted from the General Semantics Bulletin, Nos. 24 and 25 (1959), 10.

[39] Interview with Elwood Murray, Denver, Colorado, June 27, 1977.

[40] Many individuals and events influenced the development of Murray's ideas during this period. James E. Perdue noted his early interest in computers on the University of Denver campus (Interview with James E. Perdue, Associate Chancellor, State Education Department, Albany, New York, March 12, 1976). Murray's acquaintance with the writings of cyberneticists such as Ross Ashby (An Introduction to Cybernetics, 1956) and Norbert Wiener (The Human Use of Human Beings'. Cybernetics and Society, 1956) as well as other theorists such as Gregory Bateson, also influenced his thinking. Colleagues at the Universities of Denver and Southern Illinois also encouraged his work in this direction. 
[41] Murray and Hunsinger, p. 4.

[42] "Communication in the Curriculum: Interdisciplinary Analogue Laboratory on Structures, Patterns, and Themes," University of Denver summer school brochure, July 25-August 18, 1966.

[43] Murray and Perdue, "General Semantics," 42.

[44] Murray and Hunsinger, p. 6. Examples of the use of an analogue to suggest solutions to problems of communication can be found in El wood Murray, "Analogue Basis for Research in Creativity," The Journal of Communication, 13 (December, 1963), 246-51.

[45] Interview with Elwood Murray, Denver, Colorado, June 28, 1977.

[46] Copies were made of each student's final paper. These papers were then compiled into a volume, which represented the work of one laboratory.

[47] Letter from Gordon Wiseman, Ohio University, October 3, 1977.

[48] Murray and Perdue, "General Semantics," 42.

[49] Interview with Elwood Murray, Denver, Colorado, June 28, 1977.

[50] Murray and Perdue, "General Semantics," 45-46.

[51] One aspect of general semantics that may have been responsible for alienating many scholars was its extensive and often overused vocabulary. In general, one of the basic goals of Korzybski's method was to "remove the blockages we have to adequate evaluative reactions." The general semanticist holds that the chief blockages to proper evaluation come from "reactions within our heads which we confuse with the facts outside of us with which we must deal" (Elwood Murray, "Business Semantics," The Mines Magazine (March, 1944), 118). Semanticists advocate an "extensional" or "factoriented" perspective, and also suggest several other approaches in an effort to keep the individual's thought processes and language structure in correspondence with the external "realities" with which he must deal.

[52] Murray and Perdue, "General Semantics," 45-46. 
[53] Murray, "Streamlining the Speech Edifice: I," 198.

[54] Courses at the University of Denver were established to train faculty and graduate assistants to use sociodrama and group dynamics techniques in teaching speech classes (Interview with Elwood Murray, Denver, Colorado, June 25, 1977).

[55] Letter from Gladys Michaelis, New York, August 19, 1977.

[56] Paul Hunsinger, "Preface," Analogue Approaches to Problem Solving, unpublished paper, p. 3.

[57] Murray and Perdue, "General Semantics," 40.

[58] Hawes, p. X.

[59] Elwood Murray and Paul Hunsinger, "Group Creativity in the Curriculum: The Interdisciplinary Analogue Laboratory," Paper presented at a joint conference of the Institute of General Semantics and the Creative Education Foundation, State University of New York at Buffalo, June 20-25, 1971, p. 15.

[60] The Interdisciplinary Analogue Laboratory was presented by Murray at several other universities during the late 1960's, including the University of Southern Illinois, Edinboro State, and Murry State College in Kentucky. Seminars offered through the Institute of General Semantics and the University of Denver's summer programs by Murray have been widely acclaimed and have exposed educators throughout the country to the analogue approach.

[61] Paul Hunsinger experimented with the analogue approach in a basic speech course at Occidental College before assuming the chairmanship of the Department of Speech Communication at the University of Denver in 19GB. Allen Flagg, New York Society for General Semantics, adapted the analogue approach for a workshop called "The Glass Bead Game." Although the testimony of many students seems to indicate that the laboratories have been successful, this author knows of no empirical study that has yet been done to substantiate the benefits of the laboratory experience. [62] Letter from Elwood Murray, September 23, 1977.

[63] Interview with Alvin Goldberg, University of Denver, Denver, Colorado, June 26, 1977. 
[64] John Newman, "General Semantics and Academic Phagocytosis," The Quarterly Journal of Speech, 47 (April, 1961), 158.

[65] Interview with Elwood Murray, Denver, Colorado, January 6, 1976.

[66] Questionnaires were sent to over fifty of Murray's former students in an effort to ascertain their impressions of Dr. Murray's work at the University of Denver. As Dr. Roy Wood, Dean of the School of Speech at Northwestern University, summarized: “. . . there's no doubt that Elwood was viewed as being nontraditional . . . I'm certain he was always viewed as something of a maverick by his colleagues across the country" (Letter from Roy Wood, August 15, 1977).

[67] Associate Chancellor James Perdue, former Dean at the University of Denver, remarked that he had to spend a great deal of time keeping Murray "out of trouble." Many faculty members on the Denver campus resented Murray and felt that he was infringing on the territory of their discipline (Interview with James E. Perdue, Associate Chancellor, State Education Department, Albany, New York, March 12, 1976). As Donald Washburn summarized, Murray was "a bit of a character ... he had that twinkle in his eye, he was way out there, thinking thoughts that really weren't respectable in those days" (Tape-recorded comments from Donald Washburn, North Adams State College, September 2, 1977). 